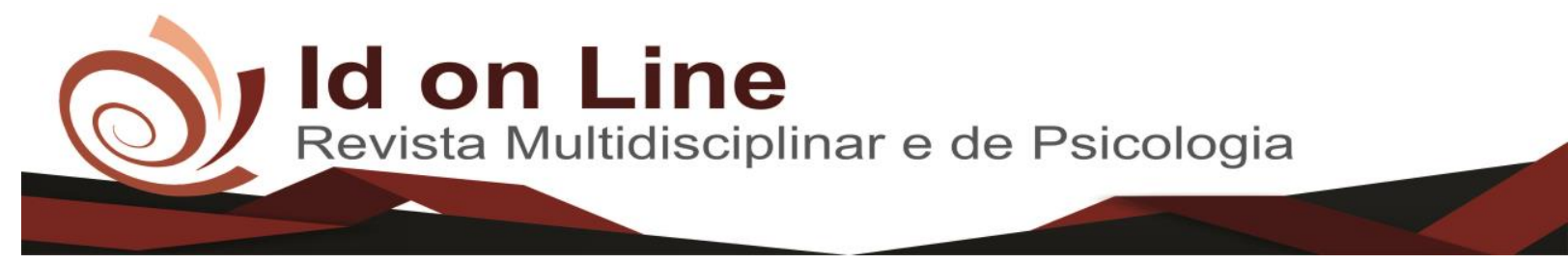

Comment

\title{
A gestão da escola na atualidade: percursos e percalços educacionais
}

\author{
Maria das Dores Lobo Silva ${ }^{1}$
}

\begin{abstract}
Resumo: A composição histórica do processo educacional tem passado por inúmeras ao longo dos anos. Nesse sentido, vale destacar que a escola pública enfrenta muitas desigualdades sociais, econômicas e culturais, Pensando nisso, esta pesquisa propõe um debate sobre as questões da gestão escolar como tema de grande relevância na construção de uma educação melhor, onde todos se sintam-se atores do processo de ensino-aprendizagem. Pretende-se nesse artigo, não apenas falar dos avanços e das características dos gestores no fazer pedagógico, mas da efetivação da qualidade em todo o processo educacional. Nessa moldura, a função da boa administração educacional no contexto social, político e econômico da educação é atualmente, além de uma exigência uma necessidade para transformação social, onde a igualdade, transparência, participação coletiva e outros fatores que tornam uma gestão escolar transparente sejam uma realidade para formar a base da educação se quer. Uma gestão com planejamento pode melhorar significativamente. Tendo em vista que há a necessidade da participação de todos, respeitando sempre as limitações, de cada aluno e o mais importante desenvolver a proposta pedagógica da melhor forma possível, tendo como principio uma educação para a formação cidadã.
\end{abstract}

Palavras-chave: Gestão democrática. Escola. Transparência.

\section{The management of school in current: educational pathways and percurses}

\begin{abstract}
The historical composition of the educational process has gone through countless over the years. In this sense, it is worth emphasizing that the public school faces many social, economic and cultural inequalities. Thinking about this, this research proposes a debate on the issues of school management as a topic of great relevance in the construction of a better education, where everyone feels actors of the teaching-learning process. The aim of this article is not only to speak of the advances and characteristics of managers in the pedagogic process, but also of the effectiveness of quality throughout the educational process. In this framework, the function of good educational administration in the social, political and economic context of education is, in addition to a requirement, a necessity for social transformation, where equality, transparency, collective participation and other factors that make transparent school management reality to form the basis of education if you want. Planning management can improve significantly. Considering that there is a need for the participation of all, always respecting the limitations of each student and the most important to develop the pedagogical proposal in the best possible way, having as a principle an education for citizen training.
\end{abstract}

Key words: Democratic management. School. Transparency. ${ }^{1}$ Graduada em Letras - pela Universidade Regional do Cariri- URCA. Pós- Graduada em gestão escolar pela Faculdade de Juazeiro do
Norte- FJN. Mestranda em Ciências da Educação Pela ANNE SULIVAN. E-mail: mariadasdoreslobosilva@ gmail.com 


\section{Introdução}

A gestão da escola pública insere-se não só nas funções didáticas, mas é um elemento muito importante tanto para o trabalho tanto do professor quanto a aprendizagem do aluno. Essa, por sua vez, é uma temática bastante discutida emlivros, revistas, seminários, debates e até mesmo em congressos em educação, assim percebendo esse elemento como algo de extrema importância na área da educação.

No entanto, vale promover hábitos novos, até porque a comunidade escolar atual exige essa postura dos gestores, não se concebendo mais a postura tradicional em que o diretor ficava apenas atrás de um birô, pois se o gestor atual tiver essa postura acaba por desgastar e desmotivar os profissionais que compõem a instituição de ensino.

Observar as falhas é o ponto principal, pois ao se fazer uma autoanalise surge à criação de novos conceitos e medidas para a correção dos mesmos. É tarefa do professor se renovar a cada dia mediante as solicitações oriundas das necessidades.

O desenvolvimento desse artigo objetiva perceber a importância do gestor administrativo na atualidade, percebendo as competências da gestão escolar, pois quando o gestor é atuante, critico e reflexivo, procura trabalhar de forma transparente e democrática contribui para a o trabalho produtivo no contexto escolar, nos diversos níveis de ensino, utilizando ferramentas que possibilitem o processo de ensino e aprendizagem.

A produção dessa pesquisa justifica-se dada a importância da postura e características que deve ter o gestor atual, partindo dessa premissa, esse trabalho pode ser considerado importante na área da gestão, tendo em vista que envolve dois elementos importantíssimo, esses sendo o professor e o aluno.

\section{Metodologia}

\section{Tipo de pesquisa}

O presente trabalho caracteriza-se como uma pesquisa bibliográfica. Para o seu desenvolvimento foi utilizada a forma exploratória, pois têm como objetivo proporcionar maior identidade e a reflexão sobre o trabalho do gestor atual na escola pública. Pois esta deve ser 
constituída de um grupo de pessoas que visem propósitos conscientes além de agir de maneira unificadora em prol de um só objetivo, o sucesso escolar tendo como foco o aluno.

Nesse sentido, procurou-se como uma prática social de extrema importância. Conhecer certa realidade e realizar uma pesquisa é de extremo valor para conhecer a essência e o processo da organização escolar no âmbito educacional. E intuito da pesquisa registrar tudo que foi pesquisado em livros, revistas, artigos para analise, e comungar da ideia de autores que vem contribuir ricamente para o dialogo sobre gestão ressalta-se alguns como: Ribeiro (2005), Paro (1996), Mendonça (2000) e Loock (2006).

\section{Resultados e Discussões}

A história da educação no Brasil foi marcada por inúmeros acontecimentos negativos como: o domínio dos jesuítas influenciado pela coroa. As poucas mudanças foram feitas em relação ao novo modelo de organização escolar, diante das incertezas. Segundo Ribeiro (2005, p. 34), "pedagogicamente essa nova organização foi de fato um retrocesso, mas representou um avanço ao exigir novos métodos”. Esse assunto é abordado na atualidade de forma critica e criativa, tendo em vista que já é possível compreender o presente quando sabe-se o que aconteceu no passado, dessa forma há a possibilidade de mudanças nas estratégias de uma prática dinâmica e ocasiona nos valores tradicionais da vida.

Com o objetivo de simplificar os estudos, diversificar os conteúdos e torná-los mais práticos para formar indivíduos negociantes surge o ensino público financiado pelo Estado e para o Estado, que atendessem a interesses do governo (RIBEIRO, 2005).

Afinal de contas qual é mesmo o papel do gestor dentro da comunidade escolar? Antes de pensar no papel do gestor é importante entender o que de fato significa gestor, essa palavra tradicionalmente falava-se diretor de escola. A função do gestor está ligada diretamente a função de gestação, de nutrir, ou seja, fazer do processo complexo, dinâmico e de aprendizagem que promova de fato a formação do cidadão. Diante disso, ser gestor é direcionar ações que alimentem o processo que muitas vezes parece ser tão difícil em algo que de fato promova uma escola para a formação dos jovens cidadãos 


\section{Gestão escolar na atualidade uma prática reflexiva}

Administrar, organizar ou gerir uma instituição não é uma tarefa fácil, trata-se de uma experiência humana feita de maneira reflexiva, promovendo a participação de todos o mais plenamente possível, este se torna um processo de mobilização de competência para execução dos objetivos de sua unidade de trabalho. (LÜCK, 2006).

Percebe-se que as práticas diárias dos gestores nem sempre condizem com o que está na proposta pedagógica ou conforme orientam as secretarias de educação, isso faz com que haja uma reflexão no sentido de querer fazer uma gestão correta para conseguir alcançar as metas desejadas. A distribuição de tarefas de forma planejada é um dos elementos primordiais para verificar se as ações individuais ou coletivas. A gestão nas escolas públicas brasileiras pode ser definidora para o sucesso da coletividade (PINTO, 1982).

Nesse sentido, concebe-se a gestão da escola uma tarefa muito complexa, onde o sucesso ou a falta dele acarreta grande responsabilidade ao diretor da escola, nesse sentido percebe-se a importância da gestão democrática e a importância de todos estarem envolvidos na gestão escolar, pois quando os atores escolares participam das tomadas de decisões, quando há êxito nas ações o sucesso é de todos quando não o fracasso também é partilhado.

A Gestão escolar pública é formada por alguns componentes como conselho escolar, (APM) Associação de Pais e Mestres, esses dois organismos colegiados participam da construção ou atualização da proposta pedagógica da escola, pois sua formação é composta por membros da sociedade civil e comunidade escolar como: alunos professores e toda a comunidade escolar.

A Lei de diretrizes e bases favorece uma gestão democrática quando:

Entre os princípios que devem nortear a educação escolar, contidos na nossa Carta Magna - a Constituição de 1988 -, em seu art. 206, assumidos no art. $3^{\circ}$ da Lei n. 9.394/96 (Lei de Diretrizes e Bases da Educação Nacional - LDB), consta, explicitamente, a "gestão democrática do ensino público, na forma desta Lei e da legislação dos sistemas de ensino" (inciso VIII do art. $3^{\circ}$ da LDB). (MEC/SEB, 2004, p. 22).

É importante ressaltar que a gestão transparente clara e objetiva visa a qualidade do ensino e trabalho pedagógico à medida que os elementos que compõem as escolas tomem consciência de seu verdadeiro papel ao promover a identidade cultural do educando e inserir no 
mundo. A possibilidade de uma ação administrativa na construção coletiva exige a participação de toda a comunidade escolar, o que resulta na democratização das relações que desenvolve na escola, contribuindo para o aperfeiçoamento administrativo e pedagógico. (HORA, 2000. p 107).

A presença de um bom diretor não é apenas desejável, mas também decisiva para um elevado nível de ensino numa escola seja ela pública ou particular. A participação possibilita à interação, a integração, a corresponsabilidade, desde as ações planejadas, isto de todos os envolvidos no cotidiano escolar

A elaboração do PP: Proposta pedagógica é algo imprescindível como perspectiva de transformação da comunidade escolar.

\begin{abstract}
A educação e os movimentos sociais organizados em defesa de um projeto de educação pública de qualidade, social e democrática for conseguido após muitas lutas. Em diferentes momentos, tais lutas se levantaram para garantir maior participação dos trabalhadores em educação nos destinos da escola, no fortalecimento dos conselhos escolares, na definição do Projeto Político Pedagógico, na defesa da eleição de diretores, da autonomia escolar e de um crescente financiamento (DOURADO, 2003, p.48-52).
\end{abstract}

É notória a necessidade de a comunidade escolar participar das decisões a serem tomadas, isso caracteriza uma gestão democrática e transparente representando assim o ápice do processo de gestão participativa. Toda a comunidade escolar deve participar da elaboração da proposta pedagógica que irá nortear o trabalho diário tanto pedagógico quanto administrativo

À medida que os educadores têm envolvido seu processo democrático e começam a entender a real função social da escola, havendo benefício favorável a toda sociedade, verificando a partir da LDB meios mais eficientes para lutar pelos seus ideais relacionando-se com a sociedade em geral (CARNEIRO, 1988, p. 79).

A educação comporta processos socializadores, porque formam os sujeitos na perspectiva de se tornarem cidadãos críticos e atuantes na sociedade. Nessa ótica a escola é vista como um espaço de socialização da cultura que constitui-se de maneira privilegiada o processo de ensino e aprendizagem com qualidade depende da organização e planejamento da gestão da escola.

De acordo com Gracindo (2000, p. 154), “a organização educacional precisa ter uma estrutura pedagógica, determinada pela finalidade, pelos fins da educação, diferentemente da 
tradicional estrutura burocrática, em que, quase sempre, os meios são mais importantes que os fins".

Dentro desse contexto, Libâneo (1997, p. 88), afirma que:

\begin{abstract}
A transformação das práticas de uma escola tem como base o próprio trabalho dos profissionais que nela atua e da participação direta dos envolvidos (alunos e pais). Além dessa condição, a transformação é resultado da responsabilidade e do compromisso de cada um na execução das atividades.
\end{abstract}

Para a organização do processo de ensino-aprendizagem o gestor deve perceber tudo em torno da rotina escolar, saber a hora de criar e inovar, analisar o desempenho da equipe, redefinir o planejamento escolar, estimular os atores escolares no sentido de produzir mais e melhor, ter objetivos claros, não temer imprevistos, superar os desafios e perceber que com a união e o trabalho em equipe o sucesso educacional é possível, mesmo diante das adversidades. Nesse sentido, o sucesso envolve vários fatores.

Parte-se então da premissa, percebe-se que o gestor escolar tem a grande missão de cuidar da gestão da escola especificamente em três níveis que de certa forma estão intimamente ligados.

Esses níveis destacam-se pela gestão de recursos pedagógicos, tecnológicos, e financeiros. Olhar para todos os processos que acontece diariamente na escola. É de fundamental importância que todos conheçam como se dão os processos uns dos outros. Nesse caso o gestor deve observar se eles estão acontecendo de forma a atingir os objetivos otimizando a participação coletiva e por fim, a gestão de pessoas que se torna a parte mais complexa, ou seja, esse é o maior desafio para o gestor na atualidade, fazer com que todos abracem a causa pela escola.

\title{
O Papel do gestor frente às relações de aprendizagem
}

O gestor escolar frente a problemática da aprendizagem é aquele que é capaz de redescobrir, capacidades, competências, habilidades e fazer com que isso eleve o verdadeiro objetivo da escola e da aprendizagem. Nesse sentido, o gestor de escola é o que exerce uma 
liderança sem que ele seja o único líder, mas que lidere um processo de condições para se realizar um trabalho com proficiência.

Nesse sentido, cabe ao gestor promover o desenvolvimento das potencialidades, físicas, cognitivas e efetivas dos alunos, por meio da aprendizagem e saberes. Nesse sentido, seu objetivo principal é a aprendizagem, que de forma organizada são viabilizadas pela organização escolar e da gestão, tendo em vista que a escola da atualidade enfrenta o desafio apresentado aos gestores educacionais, que é resgatar a cidadania da escola como uma instituição pública.

Diante disso, a escola deve basear-se em ensinamentos das correntes filosóficas educativas voltadas para o conhecimento pessoal, a valorização dos conhecimentos adquiridos em família, os valores peculiares a cada grupo social ou religioso que não seja excludente ou taxativo. Enfim, a gestão escolar deve obedecer a um conjunto de princípios norteadores extraídos do Universo Didático-Pedagógico de cunho sócio integracionista.

No entanto, convém salientar que as teorias em termos práticos ainda não e encontram assim tão bem definidas, pois em nossa história é impossível aplicar um modelo de gestão administrativa e pedagógica único na sua totalidade, haja vista a grande heterogeneidade cultural da sociedade escolar.

Entende-se, para tanto que a educação é um direito de todos e como dever o Estado deve garantir a seguridade ao indivíduo de ingressar na escola, e dela receber as orientações necessárias à sua formação pessoal e profissional asseguradas pela Lei de Diretrizes e Bases no seu artigo $2^{\circ}$ :

\footnotetext{
"A educação, dever da família e do Estado, inspirados nos princípios de liberdade e nos ideais de solidariedade humana, tem por finalidade o pleno desenvolvimento do educando, seu preparo para o exercício da cidadania e sua qualificação para o trabalho".
}

Por conta disso, a escola vem tentando promover o ensino de qualidade que atenda as prioridades do aluno que nela insere, respeitando e valorizando suas individualidades e potencialidades procurando habilidades e competências oferecendo um currículo que detenha o mínimo exigido pela lei, trabalhando a interdisciplinaridade e a transversalidade de forma agradável e interessante ao aluno.

A organização do tempo destinado para o conhecimento escolar é marcado pela segmentação primeiramente dos dias letivos e das diferentes disciplinas. 
Para alternarmos a qualidade do trabalho pedagógico faz necessário que a escola planeje-se de forma a organizar seu tempo priorizando e garantindo período de estudo e reflexão de equipes de educadores e comunidade escolar, fortalecendo a escola como instância corresponsável de formação continuada.

A escola desejada é concebida como um instrumento de transformação e deve ser organizada no âmbito interno e comunitário, valorizando e viabilizando o desenvolvimento de trabalhos educativos, querendo sempre uma escola ativa, onde todos possam trabalhar para atingir um objetivo comum, priorizando uma educação que supere a marginalização através da compreensão das mudanças ocorridas na sociedade e dê ênfase ao resgate de valores (afetividade, solidariedade, respeito) dentro de novas concepções de sociedade, escola e família.

\section{Considerações Finais}

O papel do gestor atual vai além da necessidade de se ter um diretor na escola para responder administrativamente e sim promover, além disso, o processo de ensino com qualidade, visar a participação coletiva, fazer acontecer uma gestão transparente e acima de tudo conquistar a confiança de todos.

Para fazer uma gestão dentro dessa moldura é importante que todos colaborem na articulação da escola como os professores, alunos, os pais de forma envolver toda a comunidade escolar. Para se fazer uma gestão participativa é necessário antes de tudo conceber a escola como um ambiente social, antes de tudo seguro para assim trabalhar de forma critica e reflexiva a preparação dos alunos para a vida.

Fazer esta pesquisa foi de grande valia, pois foi mais uma oportunidade de refletir sobre a gestão escolar tendo em vista que a escola nesse sentido deve ser o local de formação cidadã para todos os sujeitos, ou seja, um ambiente de atendimento as multiplicidades de experiências e vivencias em função da aprendizagem significativa.

Nesse sentido, para se fazer uma gestão participativa e promover um ensino com qualidade deve-se considerar que a formação do sujeito social deve ser permeado por diversos processos de sociabilidade, onde as relações vivencias e experiências proporcionem um leque de possibilidades existentes entre os sujeitos de normatizar as bases reguladoras da vida em sociedade. 
Esse entendimento de como conviver da melhor forma em sociedade pode se dar inicialmente na família e posteriormente pela escola, assim cada individuo estará dentro dessa lógica gozando de saberes que devem ser direcionados pela gestão de uma escola e todos que a compõem.

Por fim, a ideia e reflexão que se tira diante das leituras feitas para construir esse artigo é de que o gestor escolar deve ser pesquisador, critico e reflexivo, ser atuante naquilo que lhe compete para que por meio da investigação de sua prática possa ressignificá-la e assim poder obedecer e adequar-se as demandas sociais, porém não se conformando com a realidade que hora se apresenta, mas sim atuar diariamente de modo que possa transformá-la.

\section{Referências}

ANDRADE, Rosa Maria C. de In. Goulart, Irís (org.). A Educação na Perspectiva Construtivista. Petrópolis- RJ: Vozes, 1995.

BRASIL, Lei 9394. LDB. Lei de diretrizes e bases da educação nacional, de 20 de dezembro de 1996.

DOURADO, Luiz F. 2003. A escolha de dirigentes escolares: políticas e gestão da educação no Brasil. In FERREIRA, Naura S.C. (org.). Gestão democrática: atuais tendências, novos desafios. São Paulo: Cortez.

GIL, A. C. Como elaborar projetos de pesquisa. São Paulo: Atlas, 2002.

GRACINDO, Projeto político-pedagógico: retrato da escola em movimento. In: AGUIAR. Márcia A.; SILVA, Aída Monteiro (Org.). Retrato da Escola no Brasil. Brasília: CNTE, 2000 .

HORA, Dinair Leal da. Gestão democrática na escola. Campinas: Papirus, 1997.

LIBÂNEO. José Carlos, Concepções e práticas de organização e gestão da escola: considerações introdutórias para um exame crítico da discussão atual no brasil. Espanha Madri. 1997.

LÜCK. Heloisa. Dimensões da Gestão Escolar e suas competências. Curitiba: Positivo, 2006.

MANUAL DE APOIO E FORTALECIMENTO AOS CONSELHOS ESCOLARES. Disponível em: http://portal.mec.gov.br/programa-nacional-de-fortalecimento-dos-conselhosescolares,. Acesso em: 25 de maio de 2017. 
MENDONÇA, Erasto F. A regra e o jogo: democracia e patrimonialismo na educação brasileira. Campinas: FE/UNICAMP. 2000.

PARO, V. H. Gestão Democrática da Escola Pública. São Paulo: Ed. Ática, 1996 PINTO, Álvaro Vieira. Sete lições sobre a Administração Escolar. São Paulo: Autores Associados; Cortez, 1982.

POLATO, Amanda. Sem culpar o outro. São Paulo: Revista Nova Escola, Ano XXIV, n. 225, set/2008.

RIBEIRO, José Querino. Ensaios de uma teoria da administração escolar. São Paulo: USP, 2005.

SANTOMAURO, B. Três ideias sobre a aprendizagem. Revista Nova Escola. São Paulo, v. 25, n. 237, p. 78-81, nov. 2010.

\section{Como citar este artigo (Formato ABNT):}

SILVA, Maria das Dores L. A Gestão da Escola na Atualidade: Percursos e Percalços Educacionais. Id on Line Revista ultidisciplinar e de Psicologia, 2017, vol.12, n.39, p.386-395. ISSN: 1981-1179.

Recebido: 13.12.2017

Aceito: 15.12.2017 